\title{
Students' Critical Thinking Ability in Writing Argumentative Essay
}

\author{
Erwin Oktoma ${ }^{1}$, Muhammad Aprianto Budie Nugroho ${ }^{2}$, Yayan Suryana ${ }^{3}$, Zainal Rafli ${ }^{4}$, \\ Aceng Rahmat ${ }^{5}$ \\ ${ }^{123}$ Department of English Education, Kuningan University, ${ }^{45}$ Language Education Study Program, Post- \\ Graduate, Universitas Negeri Jakarta \\ \{1erwin.oktoma@uniku.ac.id, ${ }^{2}$ muh.apriantobn@uniku.ac.id, ${ }^{3}$ ysuryana2017@uniku.ac.id, \\ 'zainal.rafli@unj.ac.id, ${ }^{5}$ aceng.rahmat@unj.ac.id\}
}

\begin{abstract}
This research examines to analyze and find out the students' critical thinking ability in writing argumentative essay in sixth semester students of Department of English Language Faculty of Teachers Training and Education Universitas Kuningan. The focus is to know the students' level and also the way they apply the critical thinking ability in their argumentative writing. Based on the theory, there are six levels in critical thinking ability. Those are the unreflective, the challenge, beginning, practicing, advanced, and accomplished thinker. The researcher used qualitative as the design of the research. Data collection technique used in this research was questionnaire and documentation. The questionnaire was to know students' ability in applying their critical thinking in writing argumentative essay. The documentation used to gain more information about students' critical thinking ability and complete the information in the questionnaire. Based on the result of study, the students' ability in applying critical thinking is $31 \%$ in advanced thinker and practicing thinker, $18 \%$ in beginning thinker, $12 \%$ in accomplished thinker, $6 \%$ in the challenge thinker, and $2 \%$ in unreflective thinker, and the students' writing is $23 \%$ students in practicing and advanced thinker, $17 \%$ student in the challenge thinker, accomplished thinker and beginning thinker and $5 \%$ student in the unreflective thinker, and the last students' achievement of critical thinking is $44 \%$ students in accomplished thinker, $47 \%$ students in advanced thinker, $5 \%$ students in beginning thinker, $2 \%$ students in practicing thinker, $1 \%$ students in the unreflective thinker, and $1 \%$ students in the challenge thinker. Their ability in critical thinking is supported by their ability which they have. Due to the students have applied the critical thinking well, they can enhance well the critical thinking ability in argumentative essay
\end{abstract}

Keywords: Critical thinking ability; writing; Argumentative Essay

\section{Introduction}

Essay writing has different meaning of paragraph. It consists of more paragraph and more clear explanation. This kind of text is one of the student's ideas to make their writing be more logical by readers. Setiawan argued that essay writing is the expectation of the reader to write and extend a topic more extensively or complex, it must convey it into essay form, in which a kind of writing that consists of more than one paragraph [8]. In this kind of writing, the authors are not only gives information but also present an argument with the PROS (supporting ideas) and CONS (opposing ideas) of an argumentative issue [9]. A genre of writing one of which is argumentative essay that requires the student to investigate a topic; 
collect, generate, and evaluate evidence; and establish a position on the topic in a concise manner [5]. According to the meanings above, it is stated that argumentative essay is an essay that requires the writer or the author to convey their thinking in deep understanding and extensive knowledge by considering the evidence or supporting ideas to make the reader believe about the writers' argument.

At university level, critical thinking skill is essential abilities in using intellectual tools by which one appropriately assesses thinking. In this case, by utilizing critical thinking skills, students can use the intellectual tools that critical thinking offers concepts and principles that enable them to analyze, assess, and improve thinking. Working diligently to develop the intellectual virtues of intellectual integrity, intellectual humility, intellectual civility, intellectual empathy, intellectual sense of justice and confidence in reason. To put it briefly, critical thinking skills are self-improvement in thinking through intellectual tools that assess thinking [12].

The critical thinking skill will help them directly in any circumstances of information in their lesson caused by this cognitive thinking. Metacognition is One of the important characteristic of critical thinking that identified by many sources. Three sides of critical thinking are argued by Kurfiss that underlines. Those are declarative knowledge (the facts and concepts of the discipline or field), procedural knowledge (how to reason, inquire, and present knowledge about the discipline), and metacognition (being able to evaluate the outcomes of the thinking process) [6]. Specifically, "Metacognition is being aware of one's thinking as one performs specific tasks and then using this awareness to control what one is doing" [11]. Without this kind of intellectual skill, the view of students about around them will be none. Occasionally, critical thinking influences people to process the information that they get. How they can know whether the information is right or not if cannot process the information in our cognitive process about what happen around.

Thus, when they write the information in a paper, the critical thinking skill persuades them to choose the information which they write on their paper. There are many factors in building their argument in the writing work. The important factor is covered by their social life. How the environment persuades their brain to accept the information? It will process to be one of the important things for them. When their environment is not supporting their brain to process the information, it will make the teachers difficult to identify the ideas which wrote by the students in their essay. Irregularly, the students confused to describe something on the paper that actually they have known. For example, when the teachers ask to them to describe the big problem of the university, this problem will make them confused to choose the case due to many problems happen around which they trust and entrust. They confused whether their written will be same idea with each other or not. It means they have not sure with their own written work due to the differences. They cannot imagine if what they though is negative as well as their friend though it. It will disturb them and make the written work to in trouble.

Furthermore, this argumentative essay becomes one text to be observed due to those causes. Many teachers ask the students to write something with their own idea without knowing any consequences. Some of teachers think that all ideas are true but some of them say not. The same context will produce many kind of information because of this critical thinking. The level of the cognitive process in their writing will be seen clear enough. Additionally, teachers should know what the students thinking same as what they are writing on their paper. 


\section{Method}

The method of research is the common strategy that is used by research to get and collect the data needed in order to answer the research problems [1]. Considering the goal, this study is included as qualitative descriptive design since it tries to describe a phenomenon of language behavior. The researcher tried to observe the research by defining the qualitative research as the research that investigates the quality of relationships, activities, situations, materials. It focuses on understanding the context and attempts to explain the intentionality of behaviors [3]. The study takes in English Education Department of Education Faculty and Teacher Training at Kuningan University which located on Cut Nyak Dhien Street, No 36 A Kuningan. West Java. In this research, there are 87 students and 25-30 students from fourth semester students whom entering Argumentative. In this research data will be collected use the qualitative descriptive design. Occasionally, qualitative data could be much more than just words or text. It further analyzes with Photographs, videos, sound recordings, and so on. In this study the researcher needs some data to complete the research. Firstly, the researcher needs the students' writing argumentative essay to analyze and describe it in the research. Secondly, the researcher needs the students' level of critical thinking by using the rubric. Thirdly, the researcher needs the critical thinking theories for making the data valid.

The researcher needs three sources of the data that comes from the object of the data. Firstly, the researcher takes the data of students' writing argumentative essay in the field or to the direct object itself. Secondly, students' level of critical thinking can research get from the field which using the documentation technique. It will analyze by the rubric that the researcher got form the third data. The last data is critical thinking theory which is taking in the library. Cause of that, this research called library research or the research that compare with some theories inside. The researcher uses two techniques in collecting the data (Questionnaire, Documentation). In order to collect the data, the researcher will use some instruments. Moreover, some documents used to support the research that it will be analyzed by the researcher such as documentation and questionnaire.

\section{Result and Discussion}

To find the data the researcher does documentation and questionnaire. To gain the objectives of the research, the researcher chooses those process before the researcher analyzes the data systematically, accurately in data finding and discus in discussion part before gains the conclusion. As an initiation, the result of examining students taking students' critical thinking level in argumentative class will be presented first. Then, the second finding dealing with the way the students explore their critical thinking in their written work or argumentative essay will be presented as the following. This written work clarifies their skill in thinking.

\subsection{The Students' Ability of Critical Thinking in Writing Their Argumentative Essay}

Examining the ability of students' critical thinking level becomes the first focus of this research. As mentioned in the previous chapter, to answer this question, it was used a questionnaire as test to know the level of students' critical thinking. There were eighteen questions in the test. The questions related into the theory which explains six levels. Those questions divided into six parts aimed to test their level. Each part consists of three questions. This test showed that all the participants or test takers, 87 students who were divided in three classes; argumentative class A, B, and C. Each class consists of 27-30 students. The researcher 
took forty students as sample of questionnaire test and 20 students as sample of their final written work in writing argumentative essay. In this occasion the researcher tried to observe the class which was existed in the last semester. It was semester 4 while this year the students' have been in 5 th semesters. Those classes had moderate critical thinking level. It is shown from the fact that this class focus on their thinking in showing their argument. Argument concerned with the reasoning ability of the writer to present an issue logically with an overriding view. The underlined sentence shows that the students has to think logically to explain their issue on their written work. Logically thinking includes of critical thinking which need to think deeper about the issue around. Each activity which needs to think or to respond about the issue or the information, it is called critical thinking. It needs to analyze, to evaluate, to critic or to suggest is called critical thinking.

The researcher focuses on the students' ability of critical thinking level. Shortly, based on the fact said that the students' in the argumentative class included of the fifth level. It is practicing thinker. The Students' Ability in Critical Thinking Level, there are 4 students choose to leave the answer. One of students said that they did not answer the question because of they are doubt of their skill. Essentially, this is common for the students answer their skill. The strengths of believe will be challenged in this test. Nevertheless, their critical thinking is only known by themselves. How is low or how is deeper their thinking in assuming something can be felt by themselves. Hence, the researcher can show their critical thinking and help them to solve their difficulties in solving their assumptions about around

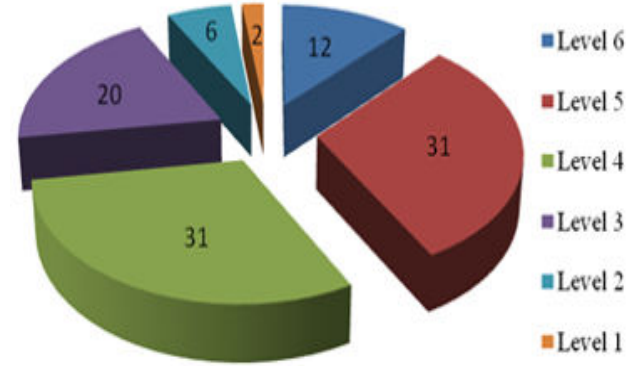

Fig1. The Percentage of Students Ability of Critical Thinking in Writing Their Argumentative Essay

In this research, the researcher uses the level of critical thinking by six levels. Those are the unreflective thinker (level 1), the challenge thinker (level 2), the beginning thinker (level 3 ), the practicing thinker (level 4), the advanced thinker (level 5), and the accomplished thinker (level 6).

\subsection{The Students' Final Written Work of Argumentative Essay and their Critical Thinking Level}

The students commonly use their own thinking and belief to write their argumentative essay. The ideas in their writing become the first focus to find out the level of their critical thinking. They write their writing with their own skill in thinking. This skill is the one focus how they trust the ideas in their thinking and how they consider the weakness and also the strength of their writing in essay. In this case, the researcher used rubric to assess the students' writing. The rubric has six criteria or the characters of their writing and also six categorizations. The six categorizations are the introduction (Background or history, define the problem, thesis statement), the main points (Body paragraphs, refutation), the conclusion, the organization, the work cited, and the last the mechanics (Sentence structure, punctuation, and capitalization). Then, six criteria describe the level of the students. The first criteria into sixth criteria describe level 1 or the unreflective thinker into level 6 or the accomplished thinker. 
Finally, the researcher took 20 students' final written work from 87 students as a sample. For instance, those samples will describe all the students in the argumentative class. Further, the researcher will find the total score of the students' level in their writing argumentative essay. Besides, the researcher decided kind of thinker with the most level or score which they get. For example, one student has score 2, 2, 3, 3, 3, 3, for instance the student will include the level 3 or the beginning thinker. On the other hand, if the student has score balance between one and another levels, they will get the higher thinker. For example, one student has score 2, $2,2,3,3,3$, shortly the student will include level 3 or the beginning thinker. In this case, the researcher will describe detail the students' writing argumentative essay based on the diagram bellow.

Table 1. The Students' Critical Thinking Level in Writing Argumentative Essay

The Students' Critical Thinking Level

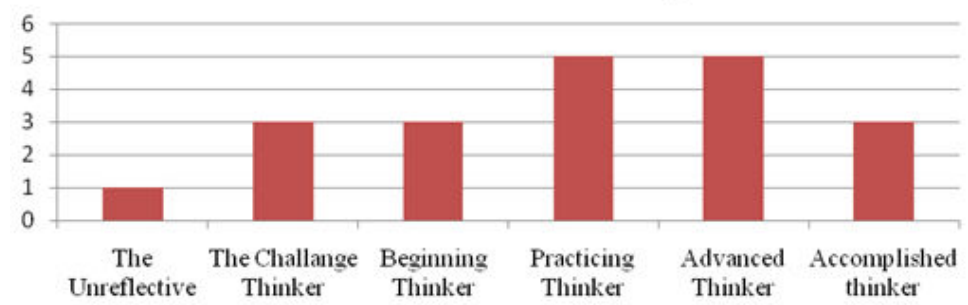

Here are the percentages of the students" critical thinking in writing essay. In this research, there are six levels which the researcher used in this rubric. Those are the unreflective thinker 5\% (Level 1), the challenge thinker 17\% (level 2), the beginning thinker $17 \%$ (level 3), practicing thinker 23\% (level 4), the advanced thinker 23\% (level 5), and the accomplished thinker $17 \%(6)$. Here are the details of the rubric score of the students' critical thinking level.

In this research, the researcher uses the level of critical thinking by six levels. Those are the unreflective thinker (level 1), the challenge thinker (level 2), the beginning thinker (level 3), the practicing thinker (level 4), the advanced thinker (level 5), and the accomplished thinker (level 6). Here are details as following:

a. The Unreflective Thinker (Level 1)

In this level, teacher is sure that the students have no motivation in joining the class. It can be seen from their present and also their habit and their attitude in the class. They have many absents in the class. This case also influences their score of achievement. Besides, they do not do their final work or any written works in their present. Further, the students which have this level only $2 \%$ or for about 2 students have no desire in following the activity in the argumentative class. They have one present, and never do the assignment or the duty from the teacher. Thus, the teacher does not know how to train the students if the student itself almost never joining the activity or the order which the teacher ask in the class.

b. The Challenge Thinker (Level 2)

In this level, the teacher challenged the students with their own thinking. There is no power in making the students smarter than before. But they should to be trained to be good writer or to be good in exploring their argument in their writing argumentative essay. Then, no percentage and no score are in this level. It means students have no skill in this level position. There are not score in this level, and also there are no students have this score. Most of them are in the good score or in the good thinking. Some of them are in the first position and some of them are in the second or third position. This case, the 
teacher succeeds to make their writing good. They have skill in thinking and sometime far of the mistake.

c. The Beginning Thinker (Level 3)

In this level the student has the basic of critical thinking. They should think critically although the result is still not good enough. This case, the teacher must has persuaded most of these students that much of their thinking left to itself is flawed and that they are capable of improving as thinkers. The teacher can use sporting analogies and analogies from other skill areas. The percentage of this level position is $4 \%$ and the students which have this score are 3 students. They have good writing but it is still not good enough because they need help from the other.

d. The Practicing Thinker (Level 4

In this level position, students have mistaken in exploring their ideas. It may have lack in thinking it with the result they have acknowledges ideas inside their writing. Their development of writing is still poor and still far o the good one. But they have expectation, desired in following and learning in the class. The percentage of this class is $3 \%$ and the total students which have this level position are three students. Most of them are in the good level position. This position is the better level for these students because these students begin to use their thinking in critical thinking. They use it although the result is far of the good one. They have the argument for those ideas, but they have not enough good ideas.

e. The Advanced Thinker (Level 5)

The students in this level regularly critique their own plan for systematic practice, and improve it thereby. They insightfully articulate the strengths and weaknesses in their thinking. They begin to develop depth of understanding the need for systematic practice in thinking, and insight into deep levels of problems in thought such consistent recognition. In this case, the students that have this thinking level are 38 students and the percentage from this level is $44 \%$. It means some of them believe of their thinking in assess their argument and compare with some trusted sources. They consider the weakness and also the strength of their ideas regularly in their writing.

f. The Accomplished Thinker (Level 6)

In this level the students think deeply for the foreseeable future, the vast majority of them will never become accomplished thinkers. They see it as a real possibility, if practicing skills of thinking becomes a characteristic of how they use their minds day to day. In this case, the students which have this level are 40 students and the percentage of this level position is $47 \%$. It means some of those students have good motivation and also high expectation in the class. They follow the class and has desire to have good idea and good writer. Some of them are never doing mistakes. Shortly based on the students' achievement above, we can know that the students have good thinker. They are in the fifth level (Advanced thinker) and the sixth level (Accomplished thinker).

From the data, the researcher found that there are two kinds of critical thinking level which the students have. Those are practicing thinker (level 4) and advanced thinker (level 5). It proves by the diagram and the table above that $29 \%$ in advanced thinker and practicing thinker, $20 \%$ in beginning thinker, $10 \%$ in accomplished thinker, $9 \%$ in the challenge thinker, and $1 \%$ in unreflective thinker. It is in line with Linda Elder with Richard Paul argued that persons are critical thinkers, in the fullest sense of the term, only if they display this ability and disposition in all, or most, of the dimensions of their lives. For instance, the students will have the higher critical thinking if they really apply this thinking deeply. 
In the table and diagram of data finding, the students also have good level in build their cognitive skill. It proves there is $47 \%$ student in accomplished thinker, $44 \%$ student in advanced thinker, $4 \%$ student in beginning thinker, 3\% student in practicing thinker, $2 \%$ student in the unreflective thinker, and $0 \%$ student in the challenge thinker. For instance, critical thinking is an educational idea [10]. It needs to be taught and learn by the students.

In the end of the discussion above, based on the three cases, the students' critical thinking level in argumentative class is in the fifth level or advanced thinker and fourth level or practicing thinker. It proved by those findings that the highest score in the students' ability in writing argumentative essay is practicing and advanced thinker, the highest score in the students' argumentative essay is also practicing and advanced thinker, and the last the highest score of the students' achievement in argumentative class is advanced and accomplished thinker. Hence, the critical thinking level in argumentative class is practicing and advanced thinker level. Thus, from the students critical thinking level can be concluded that the critical thinking level can develop well if the students really apply their ability in thinking. Though, the learning process which focuses in developing the students' critical thinking is helpful. But, it also needs help from the teachers, parents, environment and another source which can engage their critical thinking. It can be from learning autodidact or with educational school

\section{Conclusion}

Most of the students in the argumentative class have good ability, skill in writing their argumentative essay and achievement. It proves that most of them in fourth level or practicing thinker and fifth level or advanced thinker. It can be seen by the data findings that in argumentative class the higher percentages of the student's ability in critical thinking are $31 \%$ in advanced thinker and practicing thinker, and the higher percentages of the students' writing argumentative essay are $23 \%$ students in practicing and advanced thinker, and the higher percentages of the students' achievement is $47 \%$ student in advanced thinker, $44 \%$ student in accomplish thinker. It means their critical thinking ability and skill is integrated well. They really apply their skill and ability in this class as the facilitator for improving their critical thinking skill. The students really apply their cognitive skill when the teachers ask them to write their ideas in their writing of argumentative essay.

\section{References}

[1] ArifFurqon." PengantarPenelitianDalamPendidikan”. Translated from DonalAry. (Yogyakarta PustakaPelajar, 2011).

[2] C. Wallace. Critical reading in language education. (Palgrave Macmillan. 2005) accessed on 15th June 2015.

[3] Donald. Ary., et.al., Introduction to research in Education (Belmont, CA: Wadsworth, 2009), 420.

[4] H. Masduqi, 2006.Critical Thinking and Meaning. TEFLIN Journal, Vol. 22, No 2. Retrieved: 2 July 2011. P.186

[5] JackBaker-Allen Brizee, Elizabeth Angeli. "Argumentative Essay" (https//owl.english.purdue.edu.Accessed on October 3rd 2013).

[6] J. Kurfiss, (1988). Critical Thinking: Theory, Research, Practice, and Possibilities. ASHE-ERIC Higher Education Report No. 2, 1988: ERIC. 
[7] Linda E. \& Richard P.,Critical Thinking: Concepts and Tools, (The Foundation for Critical Thinking, 2006), 4th Edition.

[8] OtongSetiawan D., Essay Writing. Bandung: YRAMA WIDYA, 2009), 11

[9] OyaOzagac, Argumentative Essay, ( www.buowl.boun.edu.tr, acessed on September 2004)

[10] S.P. Norris, 1985. Synthesis of Research on Critical Thinking.Published by Association for Supervvision and curriculum development.

[11] T. A. Al-Sharadgah, Dr., Developing Critical Thinking Skills through Writing in an Internet-Based Environment. International Journal of Humanities and Social Science.

[12] The Critical Thinking Community. 2009. Defining Critical Thinking. 